\title{
Lhermitte's sign in multiple sclerosis: a clinical survey and review of the literature
}

\author{
R KANCHANDANI, JG HOWE \\ From the Department of Neurology, Chapel Allerton Hospital, and the Department of Medicine, St James's \\ University Hospital, Leeds, UK
}

SUMMARY Lhermitte's sign was experienced by $33.3 \%$ of 114 patients with multiple sclerosis, and in $16 \%$ it occurred in the first episode. Eleven patients with subacute combined degeneration of the cord due to pernicious anaemia also were reviewed, and one reported Lhermitte's sign. Review of the literature suggests that the symptom rarely occurs in other conditions except subacute combined degeneration of the cord, neck trauma, radiation myelitis and prolapsed cervical disc.

Lhermitte's sign is described in most standard neurology textbooks. ${ }^{1-3}$ All authorities agree that it is most common in multiple sclerosis but the prevalence of the symptom in this disease is unknown. We have tried to determine its prevalence in an unselected group of patients with multiple sclerosis and reviewed the literature on the other causes commonly mentioned in textbooks.

McAlpine ${ }^{4}$ appears to have been the first to use the term Lhermitte's sign in print although, in modern medical usage, the phenomenon would be called a symptom, "the consciousness of a disturbance in a bodily function". ${ }^{5}$ We have used the term since it is widely accepted and conveniently indicates the sensation with its precipitation by movement of the spine and characteristic radiation.

HISTORICAL REVIEW

The first description of the symptom was given by Marie and Chatelin in $1917^{6}$..."le blessé a la sensation qu'un courant électrique parcourt ses bras et même ses jambes ... lorsque le blessé baisse fortement la tête sur la poitrine"... Their patient had been shot in the head. The following year, Babinski and Dubois ${ }^{7}$ described a similar symptom in four soldiers of whom one had been stabbed in the neck.... "chaque fois qu'il fléchit la tete, qu'il éternue ou qu'il tousse, une sensation de décharge électrique, partant de la nuque et s'irradiant très

Address for reprint request: Dr JG Howe, Department of Medicine, St James's University Hospital, Leeds LS9 7TF, UK.

Received 21 August 1981, and in revised form 3 December 1981. Accepted 12 December 1981 violerte le long de bras et du membre inferieur droits". Thus, electric shock-like sensations radiating down the body and limbs were first recorded. Ribeton ${ }^{8}$ described 12 cases, all following head or neck trauma. He thought that the lesion responsible was spinal, even in the head injured cases, and must involve the posterior columns because of its distribution in traumatic Brown-Sequard lesions.

The first reference to the symptom in multiple sclerosis was by Beriel and Devic in $1918 .{ }^{9}$ Lhermitte, Bollak and Nicholas ${ }^{10}$ described a woman with multiple sclerosis who experienced the symptom in her first attack. They commented on the similarity of the symptom to Tinel's ${ }^{11}$ observation of tingling sensations on percussion or stretching of partlydamaged peripheral nerves. Tinel found demyelination with preserved axons in such nerves, and they referred to experimental work by Lhermitte, Claude and Roussy on "concussion" of the spinal cord which had produced demyelination.

Patrick, ${ }^{12}$ while reporting a patient with multiple sclerosis, claimed that Lhermitte's symptom occurred in tumours of the cord and Pott's disease of the spine, but gave no details. This was followed in 1933 by two reports ${ }^{1314}$ of the symptom occurring in subacute combined degeneration of the cord. In 1944 Walshe $^{15}$ drew attention to the frequent occurrence of symptoms and signs of cervical cord damage in patients who had suffered violent neck flexion at the time of a head injury. He noted that these patients were often accused of malingering because of sensory complaints, including Lhermitte's sign, which were out of proportion to the severity of the head injury and apparently unrelated to it. He noted the interval 
of a few weeks between the injury and the appearance of symptoms which Ribeton had described.

The occurrence of electric shock-like sensations in patients who had received radiation to the cervical cord was first reported by Boden in $1948.16 \mathrm{He}$ described the symptom both as a transient manifestation and as a prelude to permanent myelopathy and noted a latent interval following radiation before the symptom appeared.

A paper critical of Lhermitte's conclusions by Alajouanine, Thurel and Papaioanou ${ }^{17}$ appeared in 1949. Without reference to the cases of Walshe, Boden, Olkon or Hassin, they reported six patients with the "electric symptom" who did not have multiple sclerosis (two with atlanto-axial subluxation, two with tumours, one with a prolapsed cervical disc and one with tuberculous arachnoiditis). Their main disagreement with Lhermitte was his insistence on demyelination as the most important feature. Their cases had only "mechanical irritation" of the posterior columns and they felt an extrinsic cause should be excluded before demyelination was assumed. They also stated that poking the exposed posterior columns during operation under local anaesthetic produced a similar symptom ... "l'excitation punctiforme du cordon postérieur détermine une douleur en éclair, localisée en une zone circonscrite de la partie sous-jacente homolaterale du corps".

A definitive account of Lhermitte's sign in radiation myelopathy was published in 1964.18 Jones reviewed the literature and discussed the mechanism of the sign in detail. He pointed out that mechanical factors alone could not be responsible as Alajouanine had suggested but a medullary lesion must be present, since neck flexion, which triggered each sensation, was operating during the latent period after trauma and radiation as well as when the symptom appeared. In 1973 Gautier-Smith ${ }^{19}$ reported that 11 of 44 patients with subacute combined degeneration of the cord had described Lhermitte's sign.

\section{Method}

All patients admitted to hospital or attending the outpatient clinic with a clinical diagnosis of multiple sclerosis were studied. In addition, discharged patients listed in the departmental diagnostic index as having multiple sclerosis or subacute combined degeneration of the cord were recalled to the clinic.

On review of the history, clinical examination and laboratory tests, the patients were classified as definite, probable or possible multiple sclerosis by the criteria of Rose et al, ${ }^{20}$ and subacute combined degeneration of the cord on the basis of clinical features and the presence of vitamin B12 malabsorption or anti-intrinsic factor antibodies.
Patients considered eligible for study were asked, without using leading questions but with prompting where necessary, about the occurrence of unusual sensations. Lhermitte's sign was considered to have occurred if electric shock, tingling, rippling or other feelings had travelled rapidly along the spine. If the symptom had occurred, details of its nature and distribution, precipitating and relieving factors and the association of its onset with the onset or exacerbation of multiple sclerosis or onset of subacute combined degeneration of the cord were recorded.

\section{Results}

One hundred and fourteen patients with multiple sclerosis were studied. There were 36 men and 78 women. At the time of interview their ages ranged from 17-71 years, mean $43 \cdot 7$. Thirty-eight reported the occurrence of the symptom at some time and the details are given in tables 1 and 2 .

In 19 patients the symptom occurred during the first attack of multiple sclerosis and in two patients it was the very first symptom. It tended to disappear over a period of 4-6 weeks. A few patients continue to experience the symptom from time to time, even years after the first attack. This often happened at the time of a relapse, even when the new lesion was clearly in some other part of the nervous system. Thirty patients spontaneously used the term "electric shock" and the descriptions of the others are listed in table 3. The radiation of the sensation is given in table 4 and precipitating movements in table 5 .

Table 1 Prevalence of Lhermitte's sign in multiple sclerosis

\begin{tabular}{lrrl}
\hline & No & \multicolumn{2}{c}{ Lhermitte's sign present } \\
\hline Definite & 69 & 26 & $(37.6 \%)$ \\
Probable & 25 & 7 & $(28 \%)$ \\
Possible & 20 & 5 & $(25 \%)$ \\
Total & 114 & 38 & $(33.3 \%)$ \\
\hline
\end{tabular}

Table 2 Age at time of occurrence of Lhermitte's sign in multiple sclerosis (Range 10-62 years. Mean 35.7 years)

\begin{tabular}{lllll}
\hline Under 20 & $21-30$ & $31-40$ & $41-50$ & 51 and over \\
\hline 3 & 10 & 12 & 11 & 2 \\
\hline
\end{tabular}

Table 3 Description of sensation in multiple sclerosis

$\begin{array}{lr}\text { “Electric Shocks" } & 30 \\ \text { "Pain" } & 2 \\ \text { "Tingling, pins and needles" } & 2 \\ \text { "Ripple or shiver" } & 2 \\ \text { "Hair standing on end" } & 1 \\ \text { "Fizzing" } & 1\end{array}$


Table 4 Pattern of spread in multiple sclerosis

\begin{tabular}{crll}
\hline Down spine only & 11 & Up and down spine & 7 \\
+ both legs & 7 & Down unilateral arm and leg & 1 \\
+ arms and legs & 4 & Variable & 5 \\
+ arms only & 3 & & \\
\hline
\end{tabular}

Table 5 Movements precipitating the sign in multiple sclerosis

\begin{tabular}{lr} 
Neck flexion & 28 \\
Limb movements & 3 \\
Bending down & 3 \\
Coughing/sneezing & 1 \\
Laughing & 1 \\
More than one movement & 4 \\
Spontaneous & 2 \\
\hline
\end{tabular}

Patients reported that each paroxysm lasted for a very short time. Some were able to count aloud for us while experiencing the sensation and it usually took less than two seconds to travel the length of the body. In two cases a typical sensation occurred without a precipitating movement, and no patient reported persistence of any abnormal sensation after the first shock. Eight patients had noticed that after five or six neck movements the shock no longer occurred. None of the patients experiencing the symptom at the time of interview asked for treatment to relieve it, though all commented that it was unpleasant.

Twelve of the patients who reported Lhermitte's sign had never disclosed their experience to a doctor before we interviewed them.

Eleven patients with subacute combined degeneration of the cord were studied; one had suffered Lhermitte's sign in the first few weeks of his illness. He was 76 years old and presented with paraes- thesia in the feet and ataxia due to loss of position sense. Lhermitte's sign disappeared when B12 therapy was given. Another patient with subacute combined degeneration of the cord complained of increased tingling in her feet whenever she bent her head forward, but no sensation travelled along her body. All these patients were over 58 years and the oldest was 77 years of age.

\section{Discussion}

The prevalence of Lhermitte's sign in a group of patients with multiple sclerosis attending a general hospital neurological clinic has been determined. We observed a striking uniformity in the description of the symptom, both in patients who had described it to doctors before and in those reporting it for the first time.

Similar terms were used by patients 50 years ago. Why "electric shock" is used when so few people have ever experienced one is a puzzle; perhaps the rapidity with which the sensation travels and its brevity influence the description. A higher proportion of patients with definite multiple sclerosis reported the symptom, suggesting that some of the probable and possible cases have still to experience it.

The prevalence of the symptom has been determined in radiation myelopathy ${ }^{16}$ and subacute combined degeneration of the cord ${ }^{19}$ but not in any other condition. A review of standard textbooks and the literature on the symptom produced a number of anecdotal reports and a few reviews of larger numbers of patients which have been listed in table 6 . From this it can be seen that subacute combined degeneration, trauma, radiation and disc prolapse

Table 6 Other reported causes of Lhermitte's sign

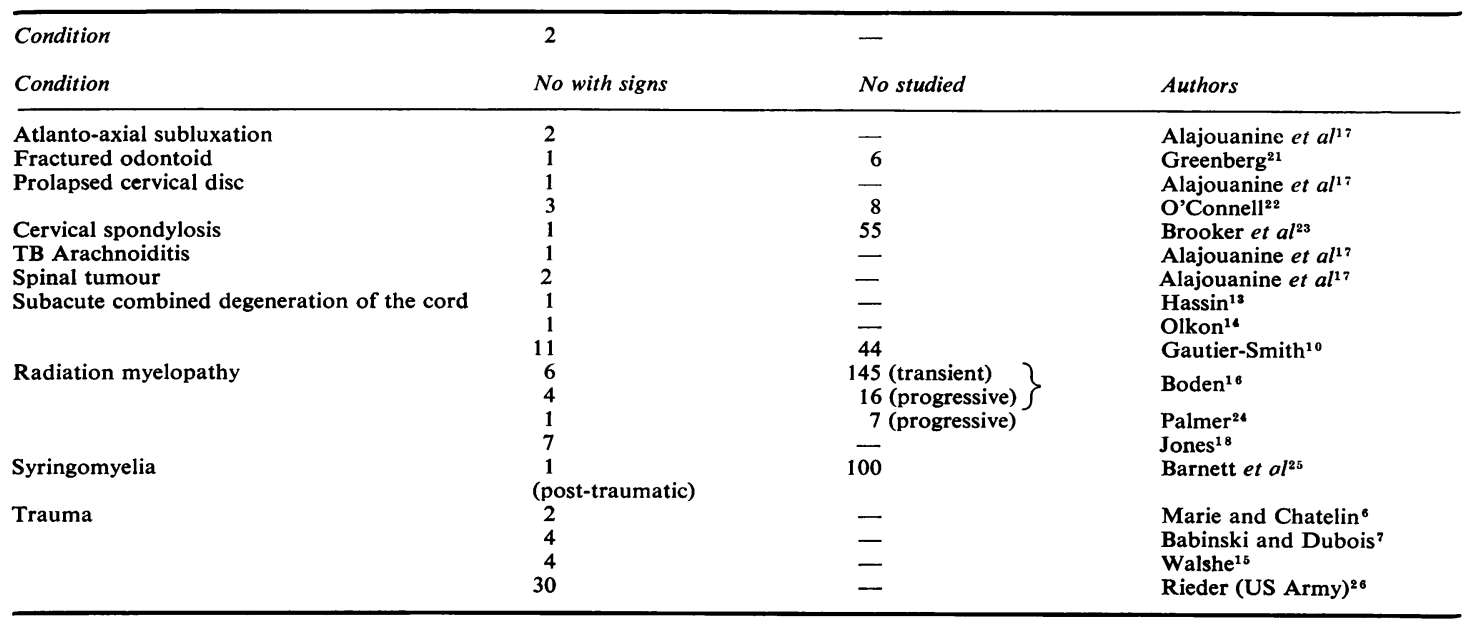


are the other conditions in which the symptom has most often been reported. In our small series of patients with subacute combined degeneration we did not find so high a proportion experiencing Lhermitte's sign as did Gautier-Smith.

Jones $^{18}$ states that Lhermitte's sign is common in cervical spondylosis, but gives no details; it is not mentioned in the reviews by Pallis et al ${ }^{27}$ or Brain et $a l,{ }^{28}$ which report in detail on a total of 95 patients with cervical spondylosis. Brooker and Barter ${ }^{23}$ describe one patient with Lhermitte's sign as a result of spondylosis. Both Bickerstaff ${ }^{2}$ and Northfield ${ }^{29}$ state that Lhermitte's sign can occur in tonsillar ectopia but it is not recorded by Appleby et $a l^{30}$ in their review of 17 patients with Arnold-Chiari malformations or by Barnett et $a l^{25}$ in their patients with tonsillar ectopia and syringomyelia.

Lhermitte ${ }^{10}$ suggested that sensory fibres stripped of their myelin sheaths were unduly excitable to percussion or elongation. Smith and McDonald ${ }^{31}$ examined sensory fibres traversing demyelinated lesions made by the microinjection of lysophosphatidyl-choline in cat spinal cord. They found spontaneously active fibres and on deforming the dorsal columns with a glass rod observed an increase in the firing rate. Fibres were most mechanically sensitive in the demyelinated region and deformations of less than $1 \mathrm{~mm}$ were effective. They demonstrated that the activity arose within the lesion. Whether these action potentials arose from demyelinated intact axons or by ephaptic spread from severed axons could not be determined.

Severed fibres have been described in multiple sclerosis lesions ${ }^{32}$ and also in subluxation injury of the cord. $^{33}$ However, myelin damage preceding axonal disruption has been reported in experimental radiation myelopathy ${ }^{34}$ and Wallerian degeneration $^{35}$ in rat spinal cord was well as in experimentally induced vitamin B12 deficiency in Rhesus monkeys. ${ }^{36}$ In both experimental radiation myelopathy and Wallerian degeneration in central fibres the earliest changes found are widening of the nodes of Ranvier and para-nodal myelin breakdown. Godwin-Austen et $a l^{37}$ found myelin damage with apparently normal axons in three patients who died with radiation myelopathy.

Agamanolis et $a l^{38}$ produced $\mathrm{B} 12$ deficiency in Rhesus monkeys and showed that the histology and localisation of lesions in the monkeys were indistinguishable from subacute combined degeneration in humans. Electron microscopy of early spinal lesions $^{36}$ revealed distension of myelin sheaths, with separation and stripping of myelin lamellae leaving denuded but intact axons surrounded by astrocytic processes and a cystic honeycomb appearance in the myelin sheath. Later total axonal degeneration was found in lesions. In a detailed study of the myelopathy of pernicious anaemia, Pant et al ${ }^{39}$ found distension of myelin sheaths and felt that the myelin was more severely involved than the axons in the early lesions; but they found no case which did not have distal tract degeneration and they concluded that there was little if any focal demyelination with preservation of axons. However, they did not study the ultrastructure of the cord and their material was from patients dying from subacute combined degeneration whereas Agamanolis et al examined material obtained after various periods of B12 deficiency.

These early changes in the myelin sheaths in Wallerian degeneration and radiation may explain the occurrence of sensory symptoms in conditions in which axonal degeneration eventually predominates. If the myelin changes found in Rhesus monkeys with B12 deficiency are assumed to occur in humans with subacute combined degeneration, then the fact that Lhermitte's sign is so much more common in multiple sclerosis and subacute combined degeneration suggests that demyelination with axonal preservation is more important for the generation of spontaneous activity than the presence of severed axons. The spread of the sensation noted by patients could indicate ephaptic activation of adjacent demyelinated axons in the posterior columns.

The spine is most mobile in the neck. During flexion the cervical cord changes in length by several centimetres and the denticulate ligaments tighten. ${ }^{40}$ This produces much more deformation of the cord than Smith and McDonald used in their experiments.

Oppenheimer ${ }^{40}$ examined the spinal cords of 14 patients with multiple sclerosis and noted that plaques were twice as common in the cervical region as in the rest of the cord. The plaques mainly occurred in the dorsal columns in relation to the point of attachment of the denticulate ligaments. He felt that this mechanical stress was in some way responsible for the more frequent occurrence of plaques at that point and for their shape. For this reason, Oppenheimer suggested that neck flexion has a detrimental effect in patients with multiple sclerosis, especially those with Lhermitte's sign.

In conclusion, Lhermitte's sign does occur in other conditions but it is so uncommon in conditions other than multiple sclerosis and subacute combined degeneration that its development in a young person, with no history of trauma to the neck or radiation, is of great diagnostic importance. Ekbom ${ }^{41}$ has reported that carbamazepine relieves the symptom, but only occasionally is it intolerable enough to warrant therapy.

We would like to thank Dr S Currie for his help and 
advice in the preparation of this report; also Dr DW Sumner and Dr S Currie for permission to examine patients under their care, and Mr E Lovatt for help with the French literature.

\section{References}

${ }^{1}$ Walton JN. Brain's Diseases of the Nervous System. 8th ed. Oxford: Oxford University Press, 1977:743.

${ }^{2}$ Bickerstaff ER. Neurological Examination in Clinical Practice. 4th ed. Oxford: Blackwell Scientific Publications, 1980;199.

${ }^{3}$ DeJong RN. The Neurologic Examination. 4th ed. Hagerstown: Harper \& Row, 1979;79, 582.

4 McAlpine D, Compston ND, Lumsden CE. Multiple Sclerosis. Edinburgh: Livingstone, 1955; 81-2.

${ }^{5}$ Butterworth's Medical Dictionary. 2nd ed. London, 1978.

${ }^{6}$ Marie P, Chatelin C. Sur certains symptomes d'origine vraisemblablement radiculaire chez les blessés du crane. Rev Neurol (Paris) 1917;24:336.

${ }^{7}$ Babinski J, Dubois R. Douleurs à forme de décharge électrique, consecutives aux traumatismes de la nuque. Presse Med 1918;26:64.

${ }^{8}$ Ribeton J. Etude clinique de douleurs à forme de décharge électrique consecutives aux traumatismes de la nuque. These de Paris 1919; No 134.

${ }^{9}$ Beriel T, Devic E. Sur un cas de douleurs à type de décharge dans la sclerose en plaques. Lyon Med $1918 ; 141: 559$.

${ }^{10}$ Lhermitte J, Bollak, Nicholas M. Les douleurs à type de décharge électrique consécutives a la flexion céphalique dans la sclérose en plaque. Rev Neurol (Paris) 1924;2:36-52.

11 Tinel J. Le signe due "fourmillement" dans les lesions des nerfs peripheriques. Presse Med 1915;23:388-9.

12 Patrick HT. The symptom of Lhermitte in multiple sclerosis. Arch Neurol Psychiatry 1930;23:1075-7

${ }^{13}$ Hassin GB. Paraplegia in flexion and the symptom of Lhermitte. Arch Neurol Psychiatry 1933;29:855-61.

${ }^{14}$ Olkon EM. Subacute combined degeneration with the symptom of Lhermitte in a pernicious anaemia case. J Nerv Ment Dis 1933;77:256-8.

15 Walshe FMR. Note on a commonly unrecognised type of injury to the cervical spine and spinal cord in association with head injury. Lancet 1944;2:173-5.

${ }^{16}$ Boden G. Radiation myelitis of the cervical spinal cord. Br J Radiol 1948;21 :464-9.

${ }^{17}$ Alajouanine Th, Thurel R, Papaioanou C. La douleur a type de decharge electrique provoquee par la flexion de la tete et parcourant le corps de haut en bas. Rev Neurol (Paris) 1949;81:89-97.

18 Jones A. Transient radiation myelopathy with reference to Lhermitte's sign of electrical paraesthesiae. Br J Radiol 1964;37:727-44.

${ }^{19}$ Gautier-Smith PC. Lhermitte's sign in subacute combined degeneration of the cord. $J$ Neurol Neurosurg Psychiatry 1973;36:861-3.

${ }^{20}$ Rose AS, Ellison GW, Myers LW, Tourtelotte WW. Criteria for the diagnosis of multiple sclerosis.
Neurology (Minneap) 1976. Abstract No 6, 20-2. ${ }^{21}$ Greenberg AD. Atlanto-axial dislocations. Brain 1968; $91: 655-84$

${ }^{22}$ O'Connell, JEA. Involvement of the spinal cord by intervertebral disc protrusions. Br J Surg 1955;43: 225-47.

${ }^{23}$ Brooker AEW, Barter RW. Cervical spondylosis. A clinical study with comparative radiology. Brain 1965;88:925-36.

${ }^{24}$ Palmer JJ. Radiation myelopathy. Brain 1972;95: 109-22.

${ }^{25}$ Barnett HJM, Foster JB, Hudgson P. Syringomyelia. London: WB Saunders Co, 1973;134.

${ }^{26}$ Rieder J. Sensations of electric shock following head injury. Arch Neurol Psychiatry 1946;56:30-40.

27 Pallis C, Jones AM, Spillane JD. Cervical Spondylosis. Brain 1954;77:274-89.

${ }^{28}$ Brain WR, Northfield D, Wilkinson M. The neurological manifestations of cervical spondylosis. Brain 1952;75:187-225.

29 Northfield DWC. The surgery of the central nervous system. Oxford: Blackwell, 1973;31.

${ }^{30}$ Appleby A, Foster JB, Hankinson J, Hudgson P. The diagnosis and management of the Chiari abnormalities in adult life. Brain 1976;91:131-40.

${ }^{31}$ Smith KJ, McDonald WI. Spontaneous and mechanically evoked activity due to central demyelinating lesion. Nature 1980;286 No 5769:154-5.

${ }^{32}$ Prineas JW, Connell F. Remyelination in multiple sclerosis. Ann Neurol 1979;5:22-31.

${ }^{33}$ Hughes JT. In: Blackwood W, Corsellis JAN, eds. Greenfield's Neuropathology. Edinburgh: Edward Arnold, 1976;665.

${ }^{34}$ Mastaglia FL, McDonald WI, Watson JV, Yogendran K. Effects of X-radiation on the spinal cord: An experimental study of the morphological changes in central nerve fibres. Brain 1976;99:101-22.

${ }^{35}$ Mastaglia FL, McDonald WI, Yogendran K. Nodal changes during the early stages of Wallerian degeneration of central nerve fibres. J Neurol Sci 1976;30: 259-67.

${ }^{36}$ Agamanolis DP, Victor M, Harris JD, Hines JD, Chester EM, Kark JA. An ultrastructural study of sub acute combined degeneration of the cord in Rhesus monkeys. J Neuropathol Exp Neurol 1978; 37:273-99.

${ }^{37}$ Godwin-Austen RB, Howell DA, Worthington B. Observations on radiation myelopathy. Brain 1975; 98:557-68.

${ }^{38}$ Agamanolis DP, Chester EM, Victor M, Kark JA, Hines JD, Harris JW. Neuropathology of experimental B12 deficiency in monkeys. Neurology (Minneap) 1976;26:905-14.

${ }^{39}$ Pant SS, Asbury AK, Richardson EP. The myelopathy of pernicious anaemia. A neuropathological reappraisal. Acta Neurol Scand 1968;Suppl 35. 44:2-36.

${ }^{40}$ Oppenheimer DR. The cervical cord in multiple sclerosis. Neuropathol Appl Neurobiol 1978;4:151-62.

${ }^{41}$ Ekbom K. Carbamazepine: a new symptomatic treatment for the paraesthesiae associated with Lhermitte's sign. $Z$ Neurol $1971 ; 200: 341-4$. 